\title{
RECONSTRUÇÃO TRIDIMENSIONAL DA FACE NOS TUMORES AVANÇADOS COM INVASÃO DA FOSSA CRANIANA ANTERIOR
}

\author{
TRIDIMENSIONAL FACIAL RECONSTRUCTION FOLLOWING MAJOR \\ RESECTION OF TUMORS INVOLVING THE ANTERIOR CRANIALFOSSA
}

\author{
Mario Sergio Lomba Galvão, TCBC-RJ ${ }^{1}$ \\ Geraldo Mattos de Sá, TCBC-RJ ${ }^{2}$ \\ Terence Farias, TCBC-RJ ${ }^{2}$ \\ Rafael Anlicoara $^{3}$ \\ Fernando Luiz Dias, TCBC-RJ ${ }^{4}$ \\ Juliano Carlos Sbalchiero, TCBC-RJ ${ }^{5}$
}

\begin{abstract}
RESUMO: Objetivo : Analisar as indicações cirúrgicas e o seguimento pós operatório, ressaltando as complicações e efetividade da abordagem multidisciplinar, para os tumores avançados da base do crânio. Método: Análise retrospectiva de 46 prontuários de pacientes submetidos à ressecção de tumores invadindo a fossa craniana anterior e reconstruídos com retalhos microcirúrgicos, operados entre março de 1990 e julho de 2002. Todos os pacientes foram operados pelo núcleo de cirurgia de base do crânio do INCA. Resultados: As estruturas mais envolvidas na ressecção foram por ordem: a órbita (76,5\%), seio maxilar (76,5\%), seio esfenoidal (63,8\%), paredes da cavidade nasal (59,5\%) e palato (42,5\%). A dura-máter estava acometida em $32,6 \%$ dos casos. A reconstrução microcirúrgica utilizando os retalhos do músculo reto abdominal foi empregada em 93,5 \% dos casos. A taxa de sucesso dos transplantes livres foi de 97,8\%. As complicações ocorreram em 58,6\% dos pacientes e as mais freqüentes foram: infecções locais (21,7\%), fístulas liquóricas (15,2\%), meningite (6,5\%) e hematoma (6,5\%). Conclusões: A reconstrução com técnica microcirúrgica permite que se realizem ressecções alargadas destes tumores com limites seguros e índices de complicações aceitáveis, permitindo a estes pacientes uma melhoria da qualidade de vida e da sobrevida, com baixo índice de recidiva.
\end{abstract}

Descritores: Neoplasias da base do crânio; Microcirurgia; Procedimentos cirúrgicos reconstrutivos.

\section{INTRODUÇÃO}

Os tumores de pele quando localizados no canto interno e externo dos olhos, base da asa nasal e conduto auditivo externo são mais agressivos e podem atingir a base do crânio ${ }^{1-4}$, produzindo o defeito tridimensional da face e do crânio que é caracterizado pela perda do contorno anatômico normal com destruição de estruturas anatômicas, como pele, tecido subcutâneo, músculos, ossos e dura-máter (Figura 1).
Os tumores avançados da cabeça e pescoço constituem uma séria realidade em virtude das precárias condições do sistema de saúde, e da situação sócio-econômica da população brasileira. São em sua maioria tumores de origem cutânea, principalmente pelo clima tropical e variabilidade étnica da população do Brasil ${ }^{5}$.

O acesso combinado crânio facial para a ressecção de tumores avançados invadindo a fossa craniana anterior tornou-se uma alternativa terapêu-

1. Cirurgião Plástico e Fundador do Serviço de Microcirurgia - Instituto Nacional do Câncer - Rio de Janeiro.

2. Cirurgião do Serviço de Cirurgia de Cabeça e Pescoço-INCA.

3. Residente do Serviço de Cirurgia Plástica Reconstrutora e Microcirurgia -INCA.

4. Chefe do Serviço de Cabeça e Pescoço - INCA.

5. Cirurgião do Serviço de Cirurgia Plástica e Microcirurgia - INCA.

Recebido em 29/07/2003

Aceito Para publicação em 21/11/2003

Trabalho realizado no Núcleo de Cirurgia da Base do Crânio do Instituto Nacional do Câncer - Rio de Janeiro. 


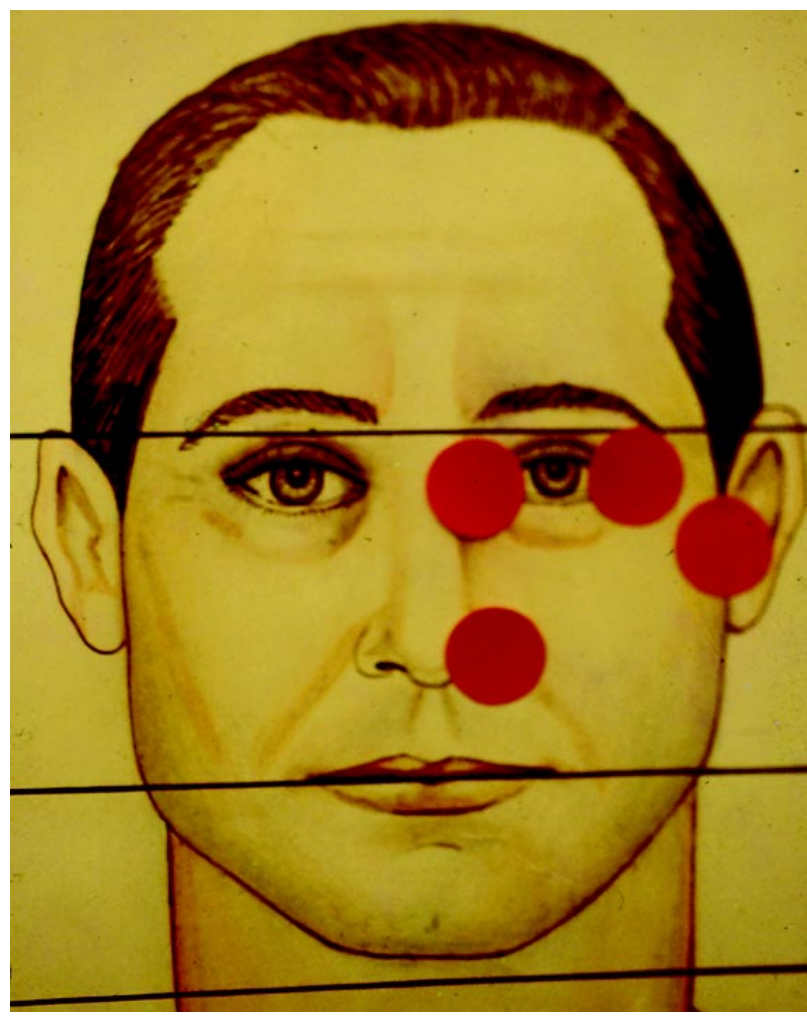

Figura 1 - Localização dos tumores de pele que podem atingir a base do crânio.

tica viável, permitindo o tratamento de casos previamente considerados inoperáveis ${ }^{1,6,7}$.

A margem de segurança nos tumores recidivados deve ser de $3 \mathrm{~cm}$ de tecido normal circunvizinho à lesão em lateralidade e profundidade .

A técnica microcirúrgica para reconstrução, com sua abundante oferta de tecido bem vascularizado, tornou-se não apenas um aliado nas cirurgias de base do crânio, mas uma condição sine qua non para que se realizem ressecções mais alargadas, inclusive com acometimento das meninges e exposição do encéfalo, limites oncológicos mais seguros, índices menores de complicações e conseqüentemente um tempo menor de internação, o que permite um retorno rápido ao convívio social ou ao tratamento coadjuvante ${ }^{1-5}$.

Portanto, para a obtenção de bons resultados com a ressecção de grandes tumores da base do crânio, a reconstrução microcirúrgica tornou-se tão importante quanto à ressecção tumoral ${ }^{8}$.

\section{MÉTODO}

Este estudo foi realizado pelo Núcleo de Cirurgia de Base do Crânio do Instituto Nacional do Cân- cer (INCA) do Rio de Janeiro- Brasil, composto pelo Serviço de Cirurgia de Cabeça e Pescoço, Serviço de Cirurgia Plástica Reconstrutora e Microcirurgia, e pelo Serviço de Neurocirurgia.

No período de março de 1990 a julho de 2002, 157 pacientes foram submetidos a ressecções oncológicas de tumores da base do crânio através de acesso craniofacial combinado. Em 46 destes pacientes foram empregados retalhos microcirúrgicos para reconstrução. Os demais pacientes foram reconstruídos com retalhos pediculados ou não necessitaram de reconstruções e não foram avaliados.

Através de uma análise retrospectiva dos prontuários destes 46 pacientes foram registrados os dados epidemiológicos, o tipo histológico, estadio do tumor , estruturas acometidas, técnica de reconstrução empregada, índice de sucesso dos transplantes, tipo de reparo da dura-máter, complicações locais e sistêmicas, taxa de recidiva, tempo de seguimento e sobrevida.

\section{RESULTADOS}

Os 46 pacientes foram submetidos a 47 procedimentos para reparação de defeitos resultantes de ressecções craniofaciais que empregaram retalhos microcirúrgicos.

A amostra foi composta por 31 homens (68\%) e 15 mulheres (32\%), com idade média de 54,3 anos variando de sete a 92 anos de idade. O diagnóstico histopatológico mais freqüente foi de carcinoma basocelular com 17 casos, seguido pelo carcinoma epidermóide com 12 casos, carcinoma adenóide cístico em seis casos, carcinoma mucoepidermóide com três casos, sarcomas de partes moles em três casos, e cistoadenoma mucinoso com um caso cada (Figura 2).

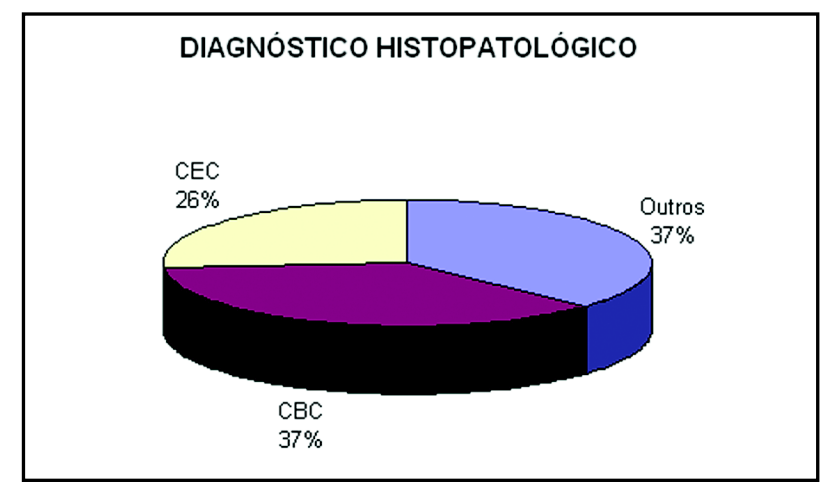

Figura 2 - Tumores da base do crânio - INCA 1990-2002. 
Todos os pacientes apresentavam tumores avançados, sem comprometimento linfonodal no pescoço ou invasão de órgãos distantes, sendo $98 \%$ estadiados como T4N0M0 e um caso estadio T3N0M0.

Os tumores envolviam predominantemente as estruturas do terço médio da face e base anterior do crânio em diferentes proporções . As estruturas mais envolvidas na ressecção por número de casos foram: componentes da órbita em 36 pacientes (76,5\%), seio maxilar em 36 (76,5\%), seio esfenoidal em 30 (63,8\%), paredes da cavidade nasal em 28 casos (59,5\%), palato em 20 (42,5\%), ocorrendo ainda em um número menor de casos a ressecção parcial ou total dos ossos frontal e zigomático, glândulas lacrimal e parótida, além da ressecção de pele da face em dimensões variáveis.

A dura-máter estava envolvida em 15 casos (32,5\%) e as técnicas utilizadas para reparação incluíram enxertia de gálea aponeurótica ou fáscia lata isoladamente em oito casos e o enxerto associado a um retalho de pericrânio nos outros sete casos.

Todos os casos aqui relatados foram reconstruídos com retalho microcirúrgico independente da reconstrução da dura-máter, que foi reparada pela equipe de neurocirurgiões.

A reconstrução microcirúrgica empregou o retalho miocutâneo do reto abdominal em 93,5\% $(n=43)$ dos pacientes, sendo o retalho antebraquial ("chinês") empregado em dois casos e o retalho miocutâneo do músculo grande dorsal empregado em um caso primário e em um caso após necrose de um retalho antebraquial. Assim sendo, os retalhos livres avaliados neste trabalho apresentaram um índice de sucesso de $97,8 \%$.

Os vasos receptores mais empregados foram à artéria carótida externa e a artéria facial assim como a veia jugular interna e o tronco tireo-linguo-facial.

As complicações pós-operatórias ocorreram em 27 pacientes (58,6\%). As complicações locais representaram $28,2 \%$ dos casos, sendo 10 casos $(21,7 \%)$ de infecções e deiscências de ferida cirúrgica e três casos (6,5\%) de osteomielite .As complicações envolvendo o sistema nervoso central corresponderam a $26,1 \%$, com sete casos $(15,2 \%)$ de fístula liquórica, três casos (6,5\%) de meningite e dois abcessos epidurais(4,3\%). Cinco pacientes (10,9\%) apresentaram complicações no retalho microcirúrgico sendo três $(6,5 \%)$ hematomas, dos quais dois foram revisados cirurgicamente, uma trombose $(2,2 \%) \mathrm{da}$ anastomose com revisão e salvamento do retalho e uma necrose total $(2,2 \%)$ de um retalho antebraquial que foi excisado e substituído por um retalho de grande dorsal.

As complicações sistêmicas corresponderam $13,1 \%$ dos casos, representadas por duas infecções respiratórias (4,3\%), uma hemorragia digestiva (2,2\%), um edema agudo de pulmão (2,2\%), uma embolia pulmonar $(2,2 \%)$ e um acidente vascular cerebral (2,2\%).

Ocorreram cinco óbitos precoces, sendo três decorrentes de infecção generalizada, um conseqüente a edema agudo de pulmão, um posterior a fístula liquórica e meningite.

Alguns pacientes apresentaram mais de uma complicação .

O seguimento médio dos pacientes foi de 25 meses variando de dois dias (óbito pós-operatório) até 83 meses. A taxa de recidiva de doença e a sobrevida média neste período foram de $7,1 \%$ e $57 \%$ respectivamente.

\section{DISCUSSÃO}

Segundo Neligan et $a l^{9}$, os tumores de base do crânio são definidos como lesões que ultrapassam os ossos da base do crânio necessitando de uma aborbagem combinada intra e extracraniana para sua ressecção.

Os tumores benignos ou malignos que acometeram em diferentes proporções a pele, seios paranasais, órbita, cavidade nasal, e atingem através do platô cribiforme a fossa craniana anterior são hoje abordados por equipes multidisciplinares que envolvem especialistas em cirurgia de cabeça e pescoço, neurocirurgia, cirurgia plástica e microcirurgia.

Nas últimas duas décadas, o avanço nas técnicas de diagnóstico por imagem e os refinamentos da técnica cirúrgica de ressecção e reconstrução tem ampliado as indicações e aumentado a complexibilidade e magnitude das ressecções craniofaciais ${ }^{4,9}$. Apesar deste avanço, a recidiva tumoral ainda ocorre em 32\% dos casos após a abordagem craniofacial ${ }^{10}$. Em nossa série, a taxa de recidiva foi de $7,1 \%$.

Neste trabalho 98\% dos pacientes apresentavam tumores em estadio T4N0M0, demonstrando um alto potencial de agressividade local com pouco potencial metastático, justificando, portanto, a radicalidade das ressecções. 
$\mathrm{O}$ acesso craniofacial combinado e a ressecção em monobloco destes tumores constitui o tratamento de escolha para tumores avançados acometendo a fossa craniana anterior, preenchendo os critérios para cura oncológica. ${ }^{5,6}$.

O método para reparação dos defeitos resultantes destas ressecções foi, até o desenvolvimento da microcirurgia, um fator limitante para a ressecção destes tumores. Atualmente, a reconstrução é uma fase tão importante quanto à ressecção para o sucesso das ressecções craniofaciais ${ }^{8}$. As vantagens dos retalhos microcirúgicos , que são ressaltadas a seguir, proporcionaram o uso cada vez menor dos retalhos locais ou miocutâneos pediculados.

As características de tamanho, volume, arco de rotação, segurança, efeitos pós-radioterapia fazem muitos dos retalhos locais deixarem de ser úteis para extensas reconstruções cranianas.Para as reconstruções acima do arco zigomático, os retalhos miocutâneos pediculados são menos seguros, apresentam maiores taxas de necroses parciais e são deficientes em volume ${ }^{11}$.

A segurança dos retalhos livres, e o volume de tecido que pode ser transplantado permitiu que se ampliassem as indicações e a magnitude das ressecções em cabeça e pescoço, já que a reconstrução deixa de ser um fator limitante ${ }^{2}$.

A microcirurgia veio oferecer um tecido altamente vascularizado e de dimensões adequadas, favorecendo uma melhor reparação dos defeitos, melhor combate à infecção e melhor efeito estético do que as reconstruções com retalhos locais . Por estas razões, a reconstrução microcirúrgica é o método de primeira escolha para o reparo de defeitos extensos que acometem a base do crânio ${ }^{1-5,8,9,12}$.

Diversos retalhos microcirúrgicos podem ser empregados para tais reparações, sendo os mais utilizados os retalhos dos músculos reto do abdome e músculo grande dorsal, o grande omento, os retalhos escapulares e o retalho antebraquial ${ }^{2,9}$.

Os retalhos livres do músculo reto-abdominal foram utilizados em 93,6\% dos casos, demonstrando claramente a opção deste serviço por este retalho. Fica clara a preferência por este retalho também nas séries de Chang ${ }^{8}$ e Neligan ${ }^{9}$, sendo descrito por Thompson e Restifo ${ }^{12}$ como o mais utilizado para reconstruções de base do crânio.

Dentre as vantagens deste retalho sobre os demais retalhos livres podemos destacar a possibilidade de realização de todos os tempos cirúrgicos sem mudança de decúbito, diminuindo o tempo cirúrgico e evitando os contratempos da manipulação do paciente com exposição do sistema nervoso central ; o longo pedículo e o diâmetro dos vasos epigástricos facilitam a reconstrução oferecendo segurança à microanastomose; o volume tecidual que pode ser obtido com a dissecção de todo o músculo reto abdominal, desde sua origem nos arcos costais, permite um excelente preenchimento de toda a cavidade criada com a ressecção, auxiliando na proteção ao reparo da dura-máter ${ }^{3}$ (Figuras 3 a 10).

A oferta de pele que pode ser carreada com retalho é das mais generosas, podendo o retalho incluir toda a área de pele irrigada pela artéria epigástrica inferior profunda. Podem ainda ser confeccionadas ilhas de pele independentes, de forma a recobrir diferentes cavidades como a oral , a nasal e ainda uma cobertura para a face. Dessa forma, permite o isolamento do SNC do meio externo e do trato aerodigestivo, reduzindo a possibilidade de fístulas e infecções ascendentes ${ }^{1-4}$. A ressecção alargada dos tumores que invadem a base anterior do crânio por si só, está sujeita a uma gama enorme de eventos clínicos desfavoráveis, associados ao normalmente comprometido estado geral dos pacientes, ao tempo prolongado da cirurgia e à complexidade da ressecção. Ao associar-se a este procedimento de grande porte, uma reconstrução complexa e de tempo prolongado como a microcirúrgica, poderia se esperar um aumento significativo desta morbidade. Entretanto, a reparação com retalhos livres reduz a morbidade cirúrgica das ressecções craniofaciais, ${ }^{6,12-14}$.

A taxa de complicação de 58,6\% é semelhante às encontradas na literatura, que variam de $16 \mathrm{a}$ $64 \%^{8,10,13,15}$. As infecções locais ocorreram em 21,7\% dos casos, sendo a complicação mais comum, talvez justificada pela inclusão em nossa avaliação de complicações locais como deiscências e infecções restritas, ou ao freqüente estado geral seriamente comprometido destes pacientes , seja pela gravidade da doença ou pelo baixo nível sócio-econômico e negligência nos cuidados com a saúde. Em outras séries ${ }^{8,13}$ há predomínio de tumores primários da mucosa dos seios paranasais; na nossa consuística são predominantes os tumores malignos de pele e em grandes proporções , muitas vezes acompanhado de infecção local o que colabora com a infecção pós-operatória.

Observamos em nossa amostra uma elevada prevalência de tabagismo, alcoolismo, maus hábitos de higiene oral e corporal, e desnutrição crônica. Co- 


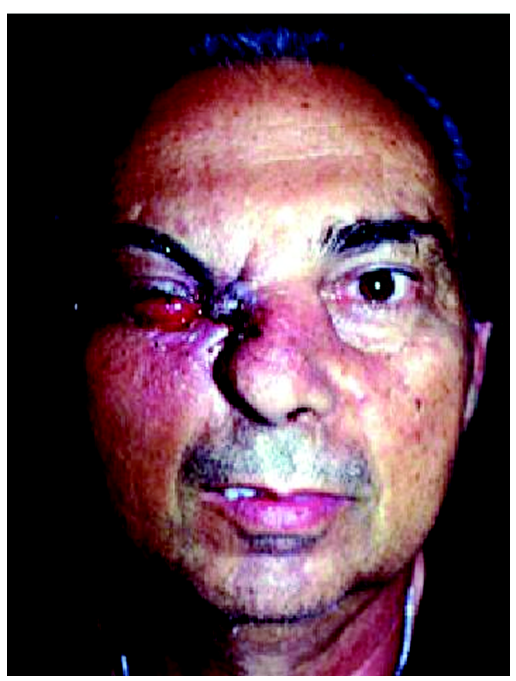

Figura 3A

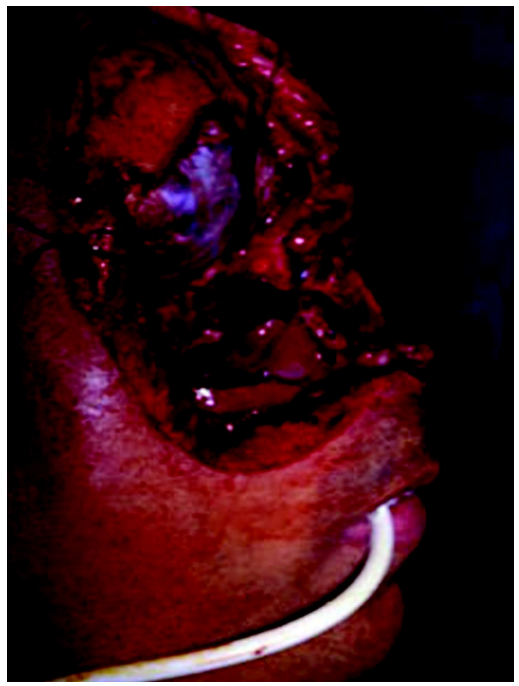

Figura 4B

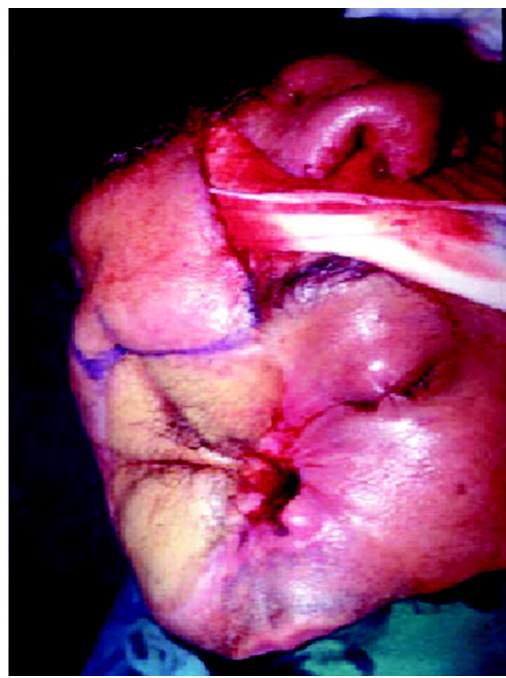

Foto 7A

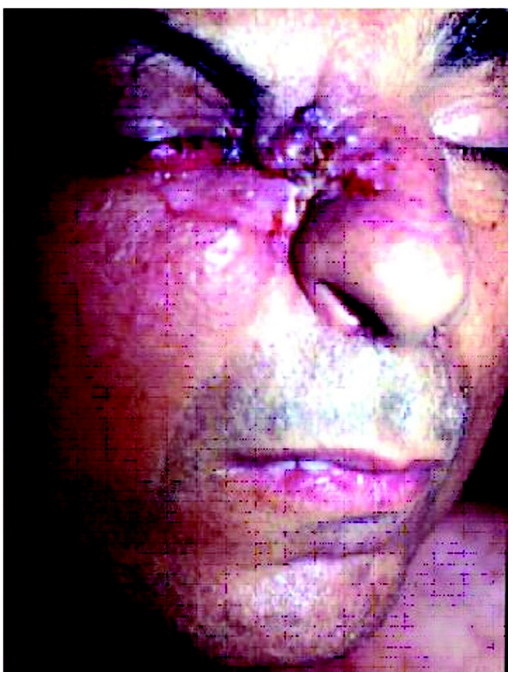

Figura 3B

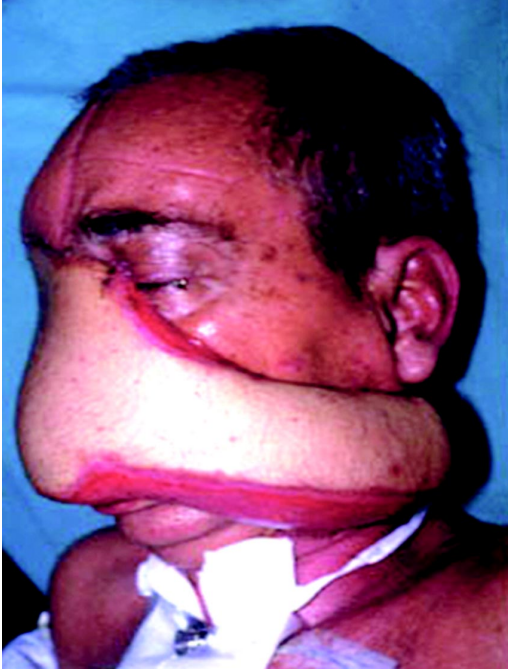

Figura 5

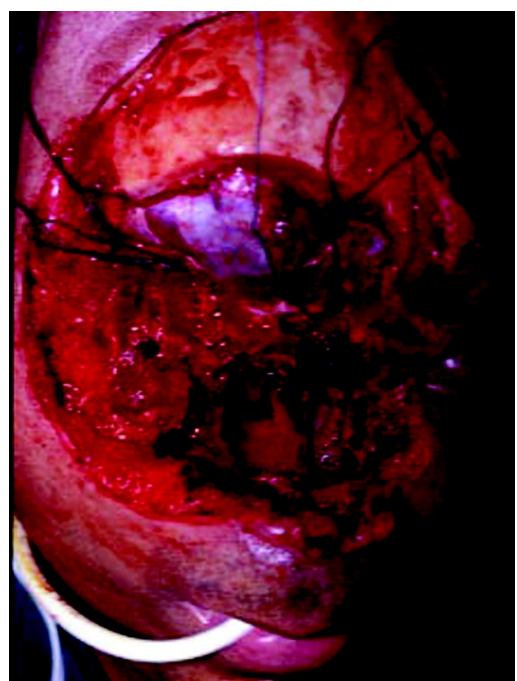

Figura 4A

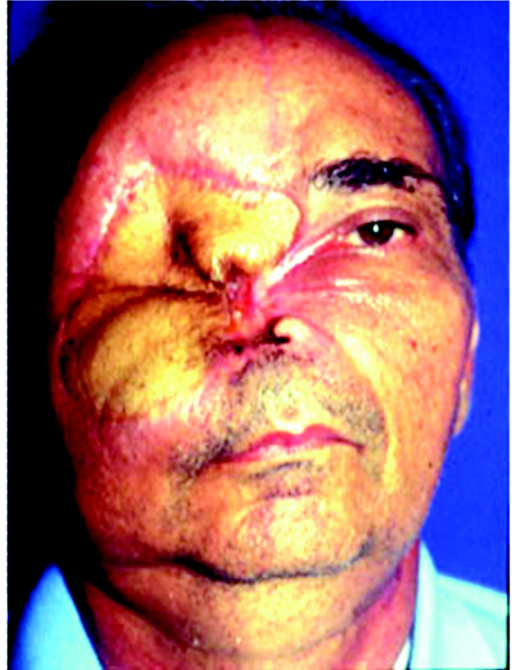

Figura 6

Figuras 3A e 3B - Pré-operatório-Carcinoma basocelular do canto interno do olho direito com invasão de base de crânio. Notar retração tumoral do supercílio direito, asa nasal direita, e, hemi-lábio superior direito.

Figura 4A - Pér-operatório: Defeito tridimensional pós-ressecção do tumor em bloco único. Foram ressecadas as seguintes estruturas anatômicas: nariz, etimóide, parte do esfenóide, maxilar, olho direito, osso frontal, e, malar.

Figura 4B - Pér-operatório: Defeito tridimensional vista lateral.

Figura 5 - Pós-operatório: 2 semanas após transplante microcirúrgico de retalho retoabdominal com microanastomose na artéria carótida externa contra-lateral e veia facial.

Figura 6 - Pós-operatório: 3 meses .Notar defeito de contorno facial com ausência do nariz e pigmentação amarelada do retalho transplantado.

Figura 7A - Pér-operatório: Pré-fabricação do nariz com retalho de converse modificado. Observar a pele da região frontal direita que foi utilizada para corrigir defeito de contorno e melhorar a coloração da pele da hemi-face direita,e, reconstrução das vias aéreas. 


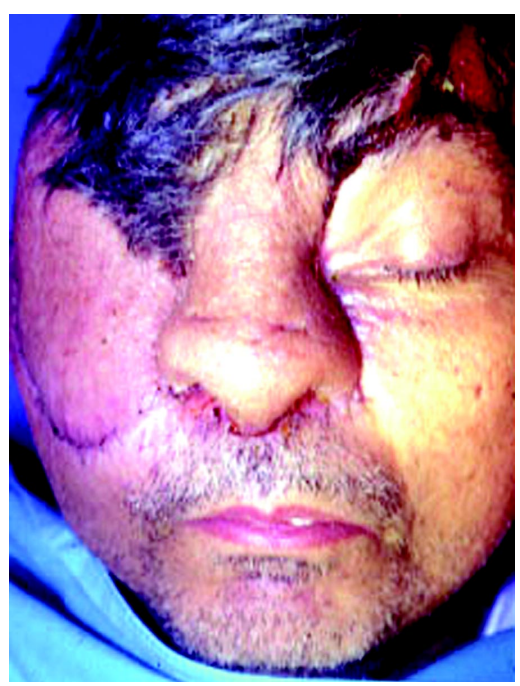

Figura 7B

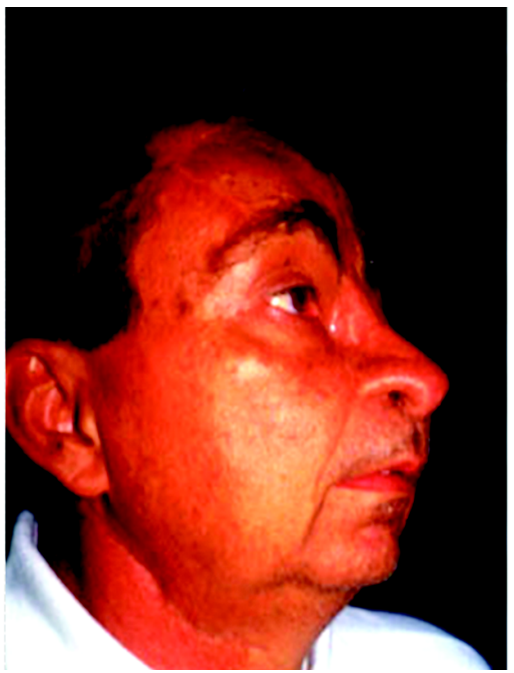

Figura 9B

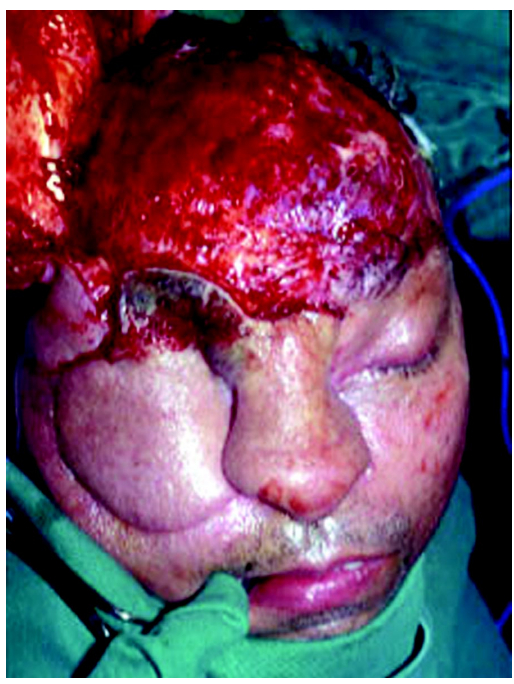

Figura 8

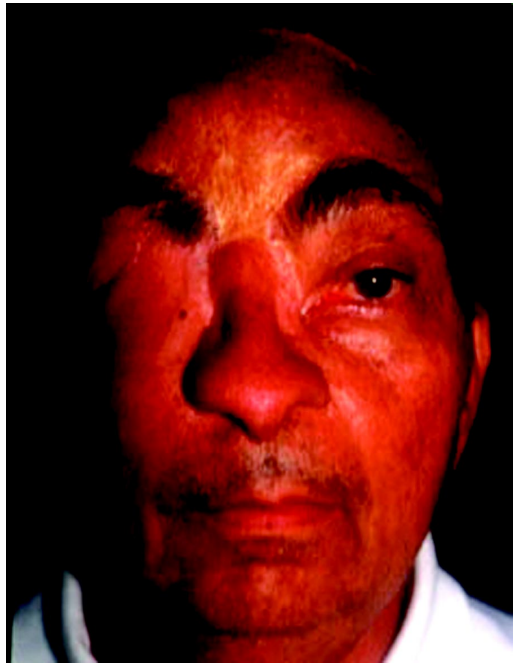

Figura 9C

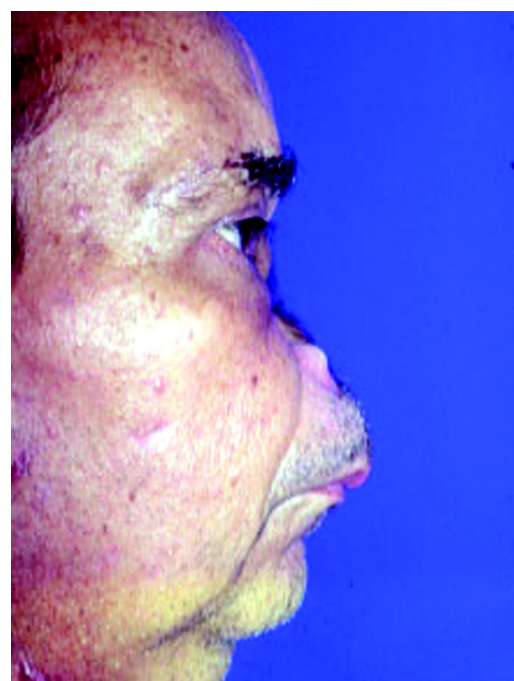

Figura 9A

Figura 7B - Pós-operatório: Resultado 1 mês após a reconstrução total do nariz e hemi-face direita.

Figura 8 - Pér-operatório: Resultado após o retorno do retalho frontal. Observar pequena área de couro cabeludo que foi deixado para reconstrução do supercílio direito.

Figura 9A- Pós-operatório: Vista lateral demonstrando defeito estético da amputação do nariz.

Figura 9B - Pós-operatório: Resultado final após a reconstrução total do nariz.

Figura 9C - Pós-operatório: 5 anos tos dentários com necrose e infecção crônica podem agir como focos sépticos no trans e pós-operatório, principalmente quando associados à imunossupressão causada pela desnutrição crônica.

Este tipo de abordagem para ressecção de tumores que expõe a dura-máter e em alguns casos o espaço subdural e o encéfalo, tem como principais complicações as infecções do sistema nervoso central, que na maioria dos casos são conseqüentes às fístulas liquóricas e infecções ascendentes a partir das vias aéreas superiores. A taxa de fístula liquórica de 15,2\% ficou dentro da média descrita nos trabalhos mais recentes que variou de 2,3 a $18 \%{ }^{8-10,12,13,16}$, e três pacientes $(6,5 \%)$ apresentaram meningite pósoperatória.
Um aspecto importante na reconstrução é a reparação da dura-máter. A possibilidade de fístula liquórica deve ser evitada a todo custo, sendo a complicação mais temível em cirurgias de base do crânio e uma das mais comuns ${ }^{1,9,15}$

Os métodos empregados no reparo da duramáter foram os enxertos de fáscia lata ou gálea aponeurótica isolados ou em associação aos retalhos de pericrânio, técnicas bastante difundidas na literatura. ${ }^{10,16,17}$

O volume dos retalhos livres preenche o espaço morto criado pela ressecção tumoral, estando em íntimo contato com o reparo da dura-máter, e contribui de forma importante para a prevenção de fístulas. 
O índice de sucesso dos transplantes de 97,8\% demonstra a segurança e aplicabilidade da técnica em cirurgias de tumores de base do crânio, e está de acordo com as estatísticas internacionais ${ }^{14,18}$.

Os pacientes, em virtude da gravidade de sua doença, são acompanhados por tempo indeterminado a nível ambulatorial. O tempo médio de seguimento foi de 25 meses, tempo este insuficiente para que possamos avaliar a sobrevida média dos pacientes, porém suficiente para mostrar uma taxa de recidiva de $7,1 \%$ neste período e uma mortalidade precoce de aproximadamente $10 \%$.

A abordagem craniofacial para ressecção de tumores da fossa craniana anterior com reconstrução empregando retalhos microcirúrgicos possibilitou uma significativa melhora na qualidade de vida e sobrevida dos mesmos com baixa taxa de recidiva, permanecendo como alternativa de primeira linha no tratamento de casos avançados. Apesar da elevada morbidade apresentada nesta série, a baixa mortalidade com elevada sobrevida justifica o uso da técnica.

\begin{abstract}
Background: The analysis of the surgical indications and the follow-up, stressing the surgical complications and efficiency of a team approach for the advanced tumors involving the anterior skull base are the purpose of the present study. Methods: The authors present a retrospective evaluation of 46 patients who underwent resections of advanced tumors involving the anterior skull base, which were reconstructed with free flaps from May, 1990 to July, 2002. Those patients have been treated by the skull base surgical team of INCA. Results: The commonest resected structures were: the orbit (76.5\%), maxilar sinus (76.5\%), sphenoidal sinus (63.8\%), nasal cavity walls (59.5\%) and palate (42.5\%). The dura-mater was involved in $32,6 \%$ of the patients. Free-flap reconstructions employing the rectus abdominis muscle flaps were the leading procedure in $93.5 \%$ of patients. The successful rate of the free-tissue transfer was $97.8 \%$. Complications occurred in $58,6 \%$ of patients, the most frequent were: local infection (21.7\%), cerebrospinal fluid leakage (15.3\%), meningitis(6.5\%) and hematoma (6.5\%). Conclusions: The microvascular free-tissue transfer reconstruction allows more extensive resections of those tumors with safety borders, presenting acceptable complication rates, offering the patients a better quality of life, longer life expectance with low incidence of recurrent disease.
\end{abstract}

Key Words: Skull base neoplasms; Microsurgery; Reconstructive surgical procedures.

\section{REFERÊNCIAS}

1. Galvão MSL, Braga ACCR, Souza JRW - A contribuição da microcirurgia reparadora no tratamento do paciente oncológico. Rev Bras Cancerol, 1984, 30(4):29-34.

2. Galvão MSL. Meeting of British Association of Plastic Surgeons Royal College of Surgeons . London, 2002. Abstract.

3. Galvão MSL, Sá GM - 2 ${ }^{\text {nd }}$ Conference Head Neck Surgery, Boston, 1988. Abstract.

4. Galvão MSL - "Reconstruction of eyebrows and eyelashes. In Smith R, Rob C (eds) - Operative surgery: fundamental international techniques. Head and neck. London. Butterworth, 1981. pp. 164-174.

5. Dias FL, Sá GM, Kligerman J - Prognostic factors and outcome in craniofacial surgery for malignant cutaneous involving the anterior skull base. Arch Otolaryngol Head Neck Surg, 1997, 123(7):738-742
6. Bootz F, Gawlowski J - Repair of anterior base of skull with free latissimus dorsi flap. Acta Neurochir (Wien), 1995, 133(3-4):195-200.

7. Yamada A, Harii K, Ueda K, et al. - Free rectus abdominis muscle reconstruction of the anterior skull base. Br J Plast Surg, 1992, 45(4):302-306

8. Chang DW, Langstein HN, Gupta A, et al. - Reconstructive management of cranial base defects after tumor ablation. Plast Reconst Surg, 2001,107(6)0:1346-1357.

9. Neligan PC, Mulholland S, Irish J, et al. - Flap selection in cranial base reconstruction. Past Reconstr Surg, 1996, 98(7):1159-1168.

10. Irish JC, Gullane PJ, Gentili F, et al. - Tumors of the skull base: outcome and survival analysis of 77 cases. Head Neck, 1994, 16(1):3-10.

11. Potparic Z, Starovic B - Reconstruction of extensive defects of the cranium using free-tissue transfer. Head Neck, 1993, 15(2):97-104. 
12. Thompson JG, Restifo RJ - Microsurgery for cranial base tumors. Clin Plast Surg, 1995, 22(3):563-572.

13. Kraus DH, Shah JP, Arbit E, et al. - Complications of craniofacial resection for tumors involving the anterior skull base. Head Neck, 1994, 16(4):307-312.

14. Jones TR, Jones NF - Advances in reconstruction of the upper aerodigestive tract and cranial base with free tissue transfer. Clin Plast Surg, 1992, 19(4):819831.

15. Dias FL, Sá GM, Kligerman J, et al. - Complications of anterior craniofacial resection . Head Neck, 1999, 21(1):12-20.

16. Izquierdo R, LeonettiJP, Origitano TC, et al. Refinements using free-tissue transfer for complaex cranial base reconstruction. Plast Reconstr Surg,1993, 92(4):567-575.
17. Langstein HN, Chang DW, Robb GL - Coverage of skull base defects. Clin Plast Surg, 2001,28(2):375-387.

18. Abard VK - "Reconstruction in cranial-base surgery". In Al-Mefty O - Surgery so the Cranial Base. Boston. Kluwer Academic Publishers, 1989, pp. 297-314.

Endereço para correspondência:

Mario S.L.Galvão

Rua Visconde Silva ,52 / 1006

Ed.Colégio Brasileiro de Cirurgiões

Botafogo, Rio de janeiro, RJ - Brasil

CEP: 22271-090-Fone: 55-21-2539-0797 